MedieKultur | Journal of media and communication research | ISSN 1901-9726

Article

\title{
Social media as communicative genres
}

\section{Stine Lomborg}

MedieKultur 2011, 51, 55-71

Published by SMID | Society of Media researchers In Denmark | www.smid.dk The online version of this text can be found open access at www.mediekultur.dk

As a focus of study, 'social media' tend to lack definitional clarity and grounding in theories of media and text. This paper establishes and discusses a conceptual framework for defining social media as communicative genres, constituted by the interplay between interactive functionalities configured at the software level and the invocation and appropriation of various software functionalities to achieve specific purposes in and through users' actual communicative practices. I suggest that social media might be seen as particularly dynamic genres, subject to continuous disruption and uncertainty, owing to their deinstitutionalised and participatory character, and the shifting roles of producers and recipients in the networks and conversations that make up social media content.

\section{Introduction}

The term 'social media' is often used in public discourse, by the media industry and in academic research, without any - or merely implicit - defining qualifications. Sometimes, 'social media' is confounded with the terms 'social software' and 'Web 2.0', to denote a new era of networked, interactive forms of communication, such as blogs, wikis, social bookmarking, social network sites, photo- and videosharing, and other, primarily Internet-based, phenomena that have emerged in recent years. Sometimes, older communication forms, 
such as e-mail, text-messaging and mobile telephony, and online chat and games are also included in the definition (e.g., boyd, 2008, p. 92; Bruns, 2008; Lüders, 2008). For example, boyd (2008, p. 92) advances a technology-based understanding of 'social media', and considers 'social media' to be an umbrella term for a range of digital media that may be used to interact with others through network technologies, such as personal computers or smart phones. Others describe 'social media' regarding the purpose of communication, contrasting it to mass-media, in that they are distinctly intended for the interpersonal communication and personalised expression of ordinary users (e.g., Lüders, 2008, p. 685). This is often framed in terms of 'user-generated content' and 'users as producers'. Related to this, 'social media' facilitate not only classic broadcasting through one-to-many communication, but also one-on-one and many-to-many forms of communication, thus implying a more distributed agency. While these descriptions are useful, they do not constitute a coherent definition of 'social media' that encompasses the complex interactional and network dynamics that characterise them, or their delimitation with respect to other digital media, in terms of their communicative attributes. In this article, I intend to provide a conceptual grounding for social media, by defining a framework for social media as communicative genres.

The aim of this article is thus to give the study of social media a theoretical and analytical grounding in genre analysis, to explore the strengths and limitations of the concept of genre, and to adjust it to this particular communicative environment. First, I introduce and motivate a genre-based framework for social media, which is followed by a detailed discussion of the relationship between media, genre and text to clarify the relative merits of conceptualising social media as genres. Then, I briefly review the concept of genre as it has been used in computer-mediated communication research, and trace its theoretical underpinnings to a functional approach to genre. Finally, I relate the concept of genre to social media as particularly dynamic genres, arguing for a stronger theoretical emphasis on the pragmatic and negotiated aspects, that is, how genres are constituted in their enactment.

\section{Conceptualising social media as communicative genres}

Strictly speaking, the term 'social media' is nonsense because it presumes that other communication media are not social. This is a fallacy: all media are social in the sense that they can be used for social purposes. We discuss the news with our friends, families and coworkers, we gather around the television set to hang out in the evening, and so forth. Using media is intertwined with, sometimes a core part of, our social activities. Thus, 'social media' needs a qualifier regarding what is special about being social in and through these Internet- and mobile phone-based services compared to other media. I would argue that social media facilitate a particular way of being social, namely a sort of everyday togetherness and relationship maintenance among participants. Social media are distinctly social because they are based on interpersonal communication and interactive content creation, typically with a personal purpose. The connections, mutual orientation, and conversations among 
users are central aspects of the social media use (Helles, 2009, pp. 7-10; Lüders, 2008). Moreover, in contrast to media such as television or newspapers, but similar to the letter and telephone, social media are the direct facilitators of, or venues for, this togetherness due to their interactive potential and invitations for contributions of active content from the users. Certainly, social media may also be used for professional purposes, such as news dissemination, celebrity branding and so on. However, these uses capitalise on the interpersonal nature of connectivity that is defining for social media.

Moreover, as I will argue more elaborately in subsequent sections, social media are not media. It is misleading to think of the above-mentioned communicative forms as media because such an understanding implies that various social media are based on different technologies. Social media form a sub-group of digital media, grouped together because they share digital technology and the aforementioned social purposes. They may be based on different software, and have different communicative features that enable them to accomplish interpersonal orientation and interactive content creation, but digital media technology underpins them all.

Instead, I propose to conceptualise social media as communicative genres, constituted at the interplay between interactive functionalities configured in software and the distinctly social purposes that users orient to in their communicative practices. The intention here is not ontological, that is, to say that social media are genres. Instead, the goal is conceptual and analytical: it is to explore what may be gained from studying social media through the lens of genre.

Genre denotes commonality or 'family resemblance' between texts both within and across media, grouped according to, for example, compositional, stylistic or thematic criteria at various levels of similarity. For instance, news journalism on different media platforms is recognisable as a genre characterised by factual content, use of sources and adherence to criteria of newsworthiness (Berkenkotter \& Huckin, 1993). News journalism is also a subgenre within the broader genre of journalism, alongside sports journalism and investigative journalism, among others. That two texts are related by genre implies that they have communicative logics and functionalities in common at some level of analysis.

The notion of genre is linked to a fundamental cognitive need to categorise and sort experiences and impressions as a means of navigating the social world. Genres are thus not only manifest in texts but also as cognitive tools for organising experience. Communicative processes of production and reception are guided by genre knowledge, which establishes a common ground in interaction. Genre knowledge is often tacit and deployed in a commonsensical way, rendering communication unproblematic. We recognise a blog as a blog, an entertainment show on television as entertainment, and so forth. Genre classifications are based on social conventions - genres are socially constructed and negotiated.

Conceptualising social media in terms of genre is useful for at least two reasons. First, because it provides 'social media' with a much needed definitional and conceptual framework that captures how different texts within the social media environment resemble 
each other and are differentiated from other texts by their communicative characteristics and social functions. The concept of genre has comparative advantage over media in this respect. It is a much more dynamic and flexible concept, well suited for describing the shifting environment and emergence and decline of forms of communication online as shaped in the communicative practices and social needs of the users. Second, the genre perspective shifts the conceptual focus from media technology as constitutive of the various social media to the actual communicative process through which different social media accomplish different things for the users, and, in this process, become imbued with meaning, and inscribed in the social fabric of everyday life. Participants' recurrent communicative practices, including the expectations and conventions they embed, are emphasised as playing a central role in constituting the various social media, in an interplay with the communicative characteristics inscribed in the software. Thus, genre involves analytic tools on the level of communicative practice. By stressing genres as orienting devices that help communicating parties reach an intersubjective understanding of the situation, the framework of genre theory offers an explanation of how users manage to successfully navigate dynamic and networked social media environments.

\section{Notes of clarification: medium, genre, text}

The concept of genre as used in this article is elastic and multidimensional: for instance, it includes differentiations at the software level and at the functional level (Finnemann, 2005, pp. 163-165). At the software level, genres, including online chat, blogs, social network sites, microblogs, and other types of social media, can be distinguished based on their communicative characteristics and interactive functions. Each of these software genres may contain functional genres, characterised by specific communicative purposes and social uses on various levels of specificity. As I have demonstrated elsewhere (Lomborg, 2009), the blog as a software genre, for example, contains a wealth of functional sub-genres that can be classified according to content, directionality and style (the personal blog, the corporate blog etc.). The overarching category of social media is understood as a system of interrelated and interdependent communicative genres. This elasticity is necessary for working with genre in relation to a broad range of texts, because it allows for systematisation by grouping similar texts at different levels of similarity. However, elasticity can also weaken the conceptual usefulness of genre because it makes it difficult to localise the genre level in concrete analyses. For purposes of clarity, the present analysis operates on a functional genre level unless otherwise stated in the text.

According to Yates and Orlikowski (1992, p. 310), genre analysis struggles with two main inconsistencies. The first concerns the level of abstraction of the concept of genre. Studies of digital communication often confound 'medium' with 'genre', and there is no conceptual agreement as to what defines media and what defines genre (Yates \& Orlikowski, 1992, p. 303). For instance, corresponding to the concept of genre I propose here, Herring et al. 
(2005) consider the blog a genre, whereas Lüders et al. (2010) describe the blog as a medium containing various genres, including the diary blog. In her conceptualisation of personal media, Lüders (2008) labels the blog a 'media form', or a subtype of digital media that is in between media and the genre level. Part of the reason for the confusion of 'medium' and 'genre' is that with digital media, software enters the equation as an intermediary between medium and genre, disturbing both concepts (Finneman, 2005). The second inconsistency is related to and concerns the normative scope of the concept of genre, that is, to what extent must norms be recognised for their recurrent communicative situation to qualify as a genre (Yates \& Orlikowski, 1992, p. 304)? How much room is there for internal variation?

Conceptualising and analysing social media as genres therefore requires some basic clarification concerning the differentiation and interrelationships between the levels of media, genre and text.

Arguing for the necessity of separating medium and genre in the analysis of social media, and using the blog as an example, Lüders et al. (2010, p. 952) conclude in a recent article that genres should be located below the software level:

\section{[...] blogs might more conveniently be seen as a medium, based upon specified software and templates, on user-friendly updating functions, and with possibilities for comments and presentation of comments in reversed order. Independently of these technical features, different blogs apply different conventions and meet different expectations. To define a genre according to its technological features reduces its important conventional dimen- sions.}

This move clearly separates medium, understood in terms of technical-material features, from genre, understood in terms of communicative conventions and expectations. Hence, genres come into play in their analysis as sub-categories of blogs - although the criteria for establishing these sub-categories remain unclear. The main deficit of their conceptual separation, however, is that by locating genre below the software level, Lüders et al. (2010) downplay the fact that the 'technological' features - meaning communicative characteristics such as reverse chronology, threaded communication, archives and commenting possibilities - that define the blog are in fact socially negotiated and therefore variable rather than fixed. These communicative characteristics have not all been common to blogging since its emergence in the mid- to late 90s (Rettberg, 2008). For instance, Blood (2004) describes how the software integration of permalinks and commenting functions in blogging software in the early 2000s developed the genre in a more conversational direction. Additionally, despite the common understanding of blogs as dialogic and bi-directional, not all blogs have commenting functions, for instance, but they are still based on blogging software, and commonly recognised as blogs. In other words, genre flexibility in the sense of communicative expectations and conventions also operate on a software level, changing the discursive functionalities, conventions and social purposes of a given genre through usage patterns over time. 
As an additional note to the software level, some of the communicative characteristics associated with blogs, such as reverse chronology as a temporal organising principle, are also characteristic of other genres within the social media environment, including Twitter and various forms of newsfeeds in social network sites. In these other services, reverse chronology as a particular software element is embedded in a different configuration programmed in software. What constitutes a blog, for instance, in relation to other software genres is the specific configuration of communicative characteristics that have become conventionalised for blogs and make blogs socially recognisable and distinct from other genres. Consequently, I find it more appropriate to bind software to the genre level.

Media may contain genres, and media often play a significant role in the recurrent situation from which the genre arises (Yates \& Orlikowski, 1992, p. 310). The Internet and the mobile phone are media or meta-media (Finnemann, 2005, p. 165; Jensen, 2010, pp. 69-70, 100) which contain a wealth of communicative genres (text-message, phone call, homepage, email, blog, social network site, online chat etc.). The communicative genres often are primarily associated with the Internet (homepage, blog, online chat etc.) or the mobile phone (text-message, phone call), but, in principle, the uses of the various genres are independent of media platforms. The microblog is an example of a communicative genre at work across media platforms, framed in the interplay between the Internet and the mobile phone as communication media.

The notion that genres are influenced by media platforms and technologies (including the physical architecture of the platform (Finnemann, 2005, pp. 161-162)) is of course not new. For instance, the TV has specific capacities influencing the genre of news because it is an audio-visual medium typically situated in the living rooms of people's homes. This allows for different modes of address by expanding the expressive register of the news genre. However, the interposition of software between media platform and genre in digital media arguably adds a new dimension to the adjustment and development of genres. Changes and adjustments at the software level, as is prevalent especially in new services, contribute to (re)shaping the communicative functions and social purposes of a given genre - for example, by making available new possibilities for interaction between users.

The differentiation of social media genres rests on a socially shaped evolutionary process in which new emergent genres are negotiated at the intersection of existing genres (digital genres as well as genres associated with print and other media technologies) (Lüders et al., 2010; Miller \& Shepherd, 2004) and the communicative potentials and constraints offered by digital media. Compared to other media technologies, the span of communicative potentials is quite broad, because digital media technology is extremely variable (Finnemann, 2005, pp. 154-160). Developers explore these communicative potentials and constraints to design and launch new software and new services, but ordinary users explore the communicative potentials too, in and through their communicative practices and interactions with peers within and across different genres. 
Genre is located as an abstract intermediary between media and texts, and both media and text play pivotal roles in the emergence, constitution and development of social media genres. Text, here, is understood broadly as communicative practice, that is, users' actual discursive (written, aural, visual, multimodal) contributions within a given social medium.

At a functional level, genre constitution entails a continuous effort and negotiation of relevant skills and knowledge through communicative practice. According to Yates and Orlikowski (1992), the constitution of a genre (or sub-genre for that matter) is only realised insofar as the communicative practices, conventions and expectations linked to the genre are socially shared and recognised among a group of users and recurrently expressed in text. Consequently, concerning the normative scope, genre constitution is a collaborative accomplishment, although individuals or relatively small groups of people may play a leading role in shaping the genre. Because social recognition plays such a vital part, actual instances of a given genre as expressed in texts are, in a sense, a negotiation of membership in the communicative circuit of a genre. For a text to be accepted as belonging to a specific genre, it must demonstrate genre principles, such as understanding and knowledge of how the genre works, and what is considered appropriate and relevant to the genre. On this premise, the text can contribute to the reshaping and evolvement of the genre. Therefore, genre development always rests on and refers to already established genre conventions and expectations (Lüders et al., 2010).

Genres are developed in the transgression of existing genre conventions in concrete communicative practice. Genres are abstract categories or ideal types that are expressed in actual text, but a text is never a pure instance of a genre. Any given blog or online chat is of course a bearer of genre traits and therefore a situated expression of the genre, but local communicative practices also constitute a unique emergent text with idiosyncratic characteristics. Different texts within a genre accomplish diverse interpretations of the genre due to local contingencies, such as the individual participants' social psychological trajectories, experiences and expectations, and the relation between the communicating parties.

\section{Genre and computer-mediated communication}

As recently argued by Lüders et al. (2010), genre is becoming ever more relevant as a concept for grasping the myriad of online communication forms. This argument is not entirely new, but has been raised sporadically in the field of computer-mediated communication since the public breakthrough of the Internet in the 1990s (e.g., Erickson, 2000; Yates \& Orlikowski, 1992; Yates \& Sumner; 1997). Yet, genre analysis has generally not gained firm footing in the study of online communication.

There is some related work on genres and computer-mediated communication, both regarding conceptual and analytical frameworks for digital genre analysis (e.g., Erickson, 2000; Yates \& Sumner, 1997) and concrete analyses of digital genres such as email (e.g., Yates \& Orlikowski, 1992), homepages (e.g., Askehave \& Nielsen, 2005), blogs (e.g., Herring et al., 
2005; Miller \& Shepherd, 2004; Sørensen, 2008, 2009; for a detailed review, see Lomborg, 2009) and mobile communication (e.g., Ling et al., 2005).

Most of the studies of genre in computer-mediated communication are grounded in either linguistic-functional genre theory (Bhatia, 1996; Swales, 1990) or rhetorical genre theory (Bazerman, 1988; Miller, 1984) and draw on classic methods for textual analysis. Despite a theoretical emphasis on studying genre as social action that accomplishes certain communicative purposes and functions for the communicators, these studies rarely take the genre analysis beyond a classificatory level that describes a given genre and its subgenres based on form and content. Exceptions include Miller and Shepherd (2004), Lüders et al. (2010), Sørensen $(2008,2009)$ and a recent anthology of genres and the Internet (Giltrow \& Stein, 2009) whose analyses focus on explaining emergent genres by connecting them to their antecedents, such as the personal blog as a reframed version of the diary. A focus on textual classification is not necessarily problematic, but it misses the wider potential of genre analysis in explaining how genres are constituted, negotiated, stabilised and destabilised in the communicative process. As a top-down approach, classification involves analysing and making inferences on the premises of existing genres, thereby potentially failing to account for any distinctly new traits that could be constitutive for new genres and that could be inferred from the grounded analysis of actual communicative practice. Genre analysis based purely on classification blurs and constrains the analytic gaze, and it might create an unfittingly static description. It loses sight of the dynamic aspects and situated uses of a given genre at a given time, including the specific social achievements of given enactments of a genre. Instead of classification, I aim to formulate an approach to genre analysis that focuses on what genres do and how genres are done and socially negotiated in actual communicative practice. As a point of departure for conceptualising social media along these lines, I begin by reviewing functional genre theory.

\section{The functional genre perspective}

Genre analysis has developed within several research disciplines, among them - and, for the present purpose, most importantly - in rhetoric, applied linguistics and media studies. In these three fields, a functional perspective of genre has become influential, one that shifts the focus of genre analysis from content/form-based description and classification, to an understanding of genre in terms of function and purpose (Andersen, 1994, p. 17).

The applied linguistic approach to genre is primarily associated with the works of John Swales (1990), whose genre definition emphasises the communicative purpose as the guiding principle for the genre:

A genre comprises a class of communicative events, the members of which share some set of communicative purposes. These purposes are recognized by the expert members of the parent discourse community and thereby constitute the rationale for the genre. This ratio- 
nale shapes the schematic structure of the discourse and influences and constrains choice of content and style. (Swales, 1990, p. 58)

The emphasis on communicative purpose, or why people in a discourse community use language the way they do, entails an analytic focus on the detailed use of language in terms of linguistic style and content. By examining these textual traits, or 'move structures' as Swales calls them, the communicative purpose or goal of the genre is uncovered.

A somewhat parallel development in rhetorical genre analysis is marked by a seminal and highly influential essay by Carolyn Miller (1984), suggesting that genre should be seen as social action. Miller builds on the works of Alfred Schutz regarding the notion of typification and the idea that humans act based on their understanding of the situation. Understanding, in turn, is generated from a process of typification or categorisation, in which humans establish recurrence and similarity between events (Miller, 1984, 156). Genre can be considered one such typified, recurrent communicative pattern:

Genre refers to a conventional category of discourse based in large-scale typification of rhetorical action; as action, it acquires meaning from situation and from the social context in which that situation arose. (Miller, 1984, p. 163)

With this definition of genre, Miller emphasises the social context in which the genre is put to use as important for understanding the social action that it accomplishes (also, Berkenkotter \& Huckin, 1993). This pragmatic concept of genre is in a sense more 'open', since a genre is not necessarily defined by a specific form or type of content (Miller, 1984, p. 155). Instead, the situated action that the genre accomplishes is highlighted as the guiding principle, implying that genres must be analysed from the bottom-up, according to the communicative purpose and rhetorical situation in which they occur. Whereas for Swales communicative purpose is framed as individual intention and function, from Miller's perspective, purpose - or 'motive', as she calls it - is rather an objectified social need (Miller, 1984, p. 163). Hence, the communicative purpose in Miller's genre theory is socially negotiated.

A core component of rhetorical genre theory is an emphasis on dynamic aspects of genre. Linking genre to the process of structuration, Yates and Orlikowski (1992) stress that genres evolve over time due to the mutual influence of the institutionalised practices and individual actions and interpretations of the genre. "A particular instance of a genre need not draw on all the rules constituting the genre" (Yates \& Orlikowski, 1992, p. 302); it suffices that the communicating parties recognise it as an instance of a specific genre. By enacting the genre only partly in compliance with the genre rules, the genre is challenged and thus must be renegotiated.

The notion of genre in media studies has its roots in literary and film theory (Andersen, 1994, p. 2; Neale, 1980; Todorov, 1990) and has been cultivated in the study of television programme genres. Whereas the linguistic and rhetorical approaches to genre are primarily concerned with the communicative purpose or social action of the author or rhetor, 
in media studies, the core achievement of the concept of genre is the idea that genres are systems of orientations, expectations and conventions that circulate between producers, texts and audiences of mass media texts (e.g., Neale, 1980, p. 19). The central element is the idea of genre as a relatively stable 'horizon of expectations', understood as assumptions or genre knowledge guiding the receiver's sense-making of a given text and a specific production model guiding the sender (Palmer, 1990, pp. 11-13). Familiarity with and the ability to distinguish a variety of genres are necessary communicative skills for the media user in the sense-making process. Accordingly, genre can be thought of as a tacit contract or a conventional relation between producer, text and receiver that ensures a mutual understanding in the communication process (Neale, 1980, p. 19). Furthermore, and in keeping with Miller's negotiated concept of genre, genres constrain communication and regulate behaviour, but they are also dynamic, shaped through interaction and changing over time as new texts within a genre reframe or challenge existing genre conventions (Neale, 1980, pp. 48-50; Palmer, 1990, p. 14).

Palmer (1990) argues that genres cannot be unequivocally defined because genres are dynamic social processes and refer to multiple dimensions within and outside the text.

Within the text, genre can be manifest at the levels of content and style, and as a communicative or compositional structure. To this, Andersen (1994) adds a pragmatic dimension to genre - how it is used and what the genre conventions accomplish for the user in a given context of use. The pragmatic dimension thus reaches beyond the text itself and inscribes production and reception in their contexts of use. With genres conceptualised as sense-making devices and horizons of expectation in the communication process, the pragmatic dimension becomes the overarching principle in the genre analysis, similar to Miller's approach.

Operating with a functional concept of genre, the linguistic, rhetoric and media-studies approaches to genre share the focus on studying the communicative purpose as manifest in genre conventions of form, style and content in recurrent communicative situations or texts. Textual analysis thus plays a pivotal role in genre studies. With the inclusion of production models guiding text production, and horizons of expectations guiding text interpretation in the concept of genre, media studies broadens the methodological and analytic scope of genre analysis, by explicitly identifying elements outside the text as starting points for understanding how genres work, and what they accomplish for the communicating parties (Andersen, 1994, pp. 10-11). Thus, from a media-studies perspective, genre analysis may include production and reception studies, using classic sociological methods such as participant observation, and interviews with media professionals and audiences (e.g., Bruun, 2010; Frandsen \& Bruun, 2005).

The functional concept of genre, outlined above, has primarily been used to study written documents (e.g., the research article, the business letter) and television formats (e.g., talk shows, news, soap operas). These are all institutionalised forms of communication in that the text is a fixed and bounded product, usually produced by a professional author 
and received by an audience. With social media, these conditions change. Ordinary users increasingly become producers, texts are constantly modified and expanded, and the separation of audiences and senders becomes increasingly obsolete. This raises the question of whether the functional concept of genre must be reformulated - theoretically and methodologically - in the study of social media.

\section{Genre theory applied to social media}

In this section, I turn to social media as communicative genres, discussing some of the challenges and opportunities that they bring to classic genre theory. Departing from a revision of the producer-text-audience model, I will argue that an inherent property of the social media environment is that genres become increasingly unstable, ambiguous and dynamic. To grasp this, genre analysis must put a stronger focus on how users negotiate genres like blogs, social network sites, chat forums, text-messages, microblogs and location-based communication services - in and through social (inter)action as framed by networked media such as the Internet and the mobile phone. In keeping with this, I will argue for the relevance of a more interactionist-pragmatic approach within functional genre theory, stressing how genres emerge and are negotiated, stabilised and destabilised online over time.

Social media may be described according to their distinction from forms of mass and broadcast communication in terms of a number of key characteristics. First, whereas in mass media there is an unequal or asymmetric communicative relation between producer and audience, because the communication is unidirectional (i.e., one-way from producer to audience), the Internet and mobile phone involve a greater potential for symmetrical communicative relations between the interacting parties. Producers have a less privileged position in the communicative process, as text-production is often collaborative and conversational in nature. Furthermore, the networked interactional structure that forms the basis of many of the currently flourishing social media implies that users communicate directly with each other, instead of through an intermediary agent (e.g., a blog or a chat room as opposed to a newspaper in which reader commentaries are selected and edited by a moderator or gatekeeper). However, despite a strong focus on individual user agency in social media, this agency is of course to a great extent framed by the institutions and companies which provide social media services and mine user data for their own purposes (e.g., van Dijck, 2009).

Second, social media, and more generally the Internet, constitute a de-institutionalised/ de-professionalised space, because ordinary users and media professionals alike have equally easy access to the digital means of production and distribution of content. For instance, social networking software from various companies is available for free, and social network sites are thus open for everyone who wants to contribute. The flip side of this is that social media require more effort from the user in order to flourish and are dependent on popularity among and participation of users to produce and filter content. Having ordinary users 
generating content implies that they too set the criteria of what is topically relevant in social media. This has sparked an enormous amount of content reflecting the personal everyday lives and moods of users, their daily efforts at coordinating social activities, and loads of informal small talk alongside more information-oriented media uses. Hence, social media bring ordinary people's everyday lives to the centre of attention.

Third, social media entail a destabilisation of the text or media product as epitomised in the concept of 'produsage' - that is, "the collaborative and continuous building and extending of existing content in pursuit of further improvement" (Bruns, 2008, p. 21). In other words, social media texts are emergent and continuously revised, and may change their course (thematic scope, style, form) over time as different users leave their marks on them.

These characteristics and dynamics inherent to the social media have significant consequences for the communicative environment, as they render genres much more dynamic and unstable, when compared to a mass media environment. The initiative concerning genre renewal in mass media is left to a fairly small group of professionals (e.g., business leaders, filmmakers or television producers) who share a certain mindset. This shared mindset may result in mass media productions being more likely to reproduce than innovate genre. Moreover, the communicating parties (author(s) and audience) are usually separated in time and space, rendering immediate and direct feedback on the text impossible. Considering this in connection with the primacy of a commercial logic in mass media of retaining audiences (for public service legitimacy or advertising revenues), institutional media outlets may be inclined to 'play it safe' and serve familiar products to the mainstream audience. Consequently, in spite of a theoretical emphasis on the dynamic aspects of genre in classic functional genre theory, the institutionalised production patterns and the separation of producers and audiences in time and space may in fact significantly slow down genre development.

In contrast, social media genres may be anticipated to exhibit more dynamic and unstable genre patterns because a larger and more diverse number of producers and audiences are in direct dialogue, making feedback much more instantaneous, especially in synchronous short-form genres such as online chat and microblogging. As a consequence of the very direct feedback structure online, genres are likely to be organised in a more ad-hoc way, as the horizons of expectations of the user/producers may be constantly challenged, reproduced and adjusted through interaction with fellow user/producers. The argument made here is a theoretical one that must be tested through empirical analysis. In addition, because communication in many social media genres is embedded in practices of network creation and maintenance, the dynamics of networking influence genre development. The network structure may entail less tightly knit norms and thus greater genre variety, but the dependence on connecting with others in networks may also generate a pressure towards conformity. For instance, Lomborg's (2011) qualitative empirical work on ordinary users' appropriation of Twitter in everyday life suggests that densely connected and tightly-knit clusters of users may involve more stable expressions of Twitter as a communicative genre, 
because users are more inclined to 'agree' on its basic conventions, whereas the norms and expectations guiding the enactment of Twitter may be less firmly constituted in loosely structured and highly distributed networks of users. Such networks may thus display greater fluctuation in the expression of genre. This indicates that the specific configuration of the network in which a given genre is enacted influences the degree of genre stability. Further empirical work remains to be done clarifying and solidifying such claims about the role of network dynamics in the negotiations of a given genre.

When the ordinary user/producer, rather than media institutions, defines the genre conventions of various social media, this potentially creates more ambiguity, more variation and less stability in the expression of a given genre. The wealth of sub-genres and hybrids within the blog genre provides empirical illustration of this (Lüders, 2008, p. 688). Moreover, genre overlaps, mixings and mergers may be more common; in other words, Twitter and other microblogging systems mix core software features from social network sites (articulation of networks of friends or followers) with elements from blogging (e.g., author-centeredness, reverse chronology). Genre mixing is also widespread within individual texts: a specific blog or microblog may combine, for example, political statements and arguments with notes on the author's private life (e.g., Lomborg, 2009). Along similar lines, users often communicate through multiple genres simultaneously with the same people (e.g., Helles, 2009), possibly implying that genre norms linked to, for instance, conversations in text-messages migrate to microblogs or other social media. Another example of the intersection of separate genre circuits is the practice of synchronising profiles, which involves interlinking, for instance, one's blog, Twitter and Facebook accounts so that new posts in one of these appear automatically in the other two.

Concerning more fundamental genre adjustments, Twitter is a particularly vivid example of the social shaping of genres and genre change from the bottom up. As a proponent of the microblogging genre, Twitter was originally designed as a communicative network in which individuals could speak their minds in 'tweets' and other users could read what they wrote - it was not really designed for conversation. However, users themselves started to have conversations and to spread each others' tweets, resulting in, for instance, the addressivity function of the @ sign and the RT (retweet) function being embedded in the design over time (boyd, Golder \& Lotan, 2010). By making changes at the software level, Twitter has sought to adjust the service to the users' needs and practices.

The dynamism of social media is perhaps most evident in the almost incessant emergence of new services that enter the genre ecology and potentially destabilise the existing genres. The advent of the microblog and Twitter and Facebook in particular, for instance, destabilised the blog at first. Its short form implied easy and less time consuming communication than the often-lengthy postings prevalent in blogs, and microblogs quickly caught popularity. This led some media commentators to claim the death of the blog - outcompeted by a simpler and faster genre. Of course, this claim was overly dramatic, but when 
new genres gain traction, the functions and social uses of existing genres are readjusted and their purposes redefined.

Social media constitute a quite chaotic communicative environment in which genres are in constant flux. Ironically, this is the very reason why genres and genre knowledge are still extremely important orientation and sense-making devices for users in that they frame communication with certain conventions and expectations and thus provide a sense of 'fixity' (Lüders et al., 2010; Yates \& Sumner, 1997).

\section{Conclusion}

\section{- towards a functional-pragmatic genre analysis of social media}

Rather than rejecting functional genre theory and analysis for the study of social media, I suggest that it can be attuned to the interactional and networked logic of social media, by placing stronger emphasis on the pragmatic dimension of genre (Andersen, 1994; Miller, 1984). This includes a focus on genre enactments, and sensitivity to social interaction and interactive dynamics as important components in the negotiation of genre (Yates \& Orlikowski, 1992).

Reformulated along pragmatic lines, then, genre analysis aims to document broader patterns of interaction. Regarding the actors' genre knowledge and expectations, a central analytical task is to identify the interactional skills that are necessary to engage in meaningful conversation. What types of knowledge are considered important in a given genre, to what degree is genre knowledge shared and agreed upon, and what are the basic components of this knowledge? How do genre knowledge and genre patterns stabilise and destabilise over time through participants' practices?

Social media lend themselves very well to the study of genre negotiations because their texts make visible the process of mutual adjustment and fine-tuning of expectations concerning their interaction in a constant process of feedback on appropriate and relevant behaviours. The communicative practices of ordinary users in blogs, social network sites, online chat, location-based services and the like are thus basically genre norms and conventions in the making.

This restatement of the aims of genre analysis maintains that a genre analysis must take its starting point in the communicative practices that characterise specific instances of the genre. That is to say, classic textual analysis remains central to genre analysis. However, methodologically and analytically it opens a range of new possibilities for genre analysis. If genre is enacted through social interaction, this implies that genre can be studied and analysed within an interactionist framework focusing on how users 'do' genre - that is, on how users accomplish meaningful communication by bringing interactional norms, conventions and tacit genre knowledge into play in the communicative process, and on how they demonstrate genre skills. Accordingly, analytic frameworks such as ethnomethodology, conversation analysis, frame analysis and discursive psychology may prove highly useful. Along with 
these frameworks, methods like (participant) observation may enter the methodological toolbox of genre analysis to complement text analysis and individual interviews, and possibly offer new trajectories and fuel to the study of genre.

In this article, I have outlined a conceptual framework for the study of social media based upon functional-pragmatic genre theory, fundamentally seeing social media as a subgroup of digital media that are characterised by a distinct social purpose at the communicative level (interpersonal communication and togetherness), and interactive features at the software level (e.g., possibilities for connecting with peers through interactive content creation). From this basis, I have argued that when analysing social media from a genre perspective, the emphasis must be put on studying 'doing genre' in the sense of explicating genres as enacted and negotiated in and through social practice. In particular, sensitivity to interactional dynamics becomes crucial in a genre analysis of social media.

I have further argued that social media constitute a particularly dynamic genre environment, in part because of the very direct feedback structure online and the large number of ordinary users engaged in genre production and negotiation through participation in social media. Emergent texts mix genres at a high pace, genres intersect when user interactions unfold across genres, and new genres continuously emerge from combinations of existing genres. Due to this potential dynamism, ambiguity and instability, a genre analysis of social media must be sensitive to the context in which genres emerge, and to how genres are configured, negotiated, stabilised, and possibly destabilised over time. Along these lines, a much overlooked analytic trajectory concerns the question of how and why some sites and genres grow enormously popular, widely mastered and appreciated in everyday life across demographic groups and cultures (social network sites such as Facebook being the obvious example), while others (e.g., location-based genres and to some extent blogs and Multi User Dungeons (MUDs) MUDs)) remain niche-oriented or even perish over time.

\section{References}

Andersen, M.B. (1994). TV og genre. In Dahlgren, P. (Ed.), Den Mångtydiga Rutan. Stockholm: Skriftserien JMK.

Askehave, I. \& Nielsen, A.E. (2005). Digital genres: a challenge to traditional genre theory. Information Technology \& People, 18(2),120-141.

Bazerman, C. (1988). Shaping Written Knowledge: The Genre and Activity of the Experimental Article in Science. Madison: University of Wisconsin Press.

Berkenkotter, C. \& Huckin, T.N. (1993). Rethinking genre from a socio-cognitive perspective. Written Communication, vol. 10(4), pp. 475-509.

Bhatia, V.K. (1996). Methodological issues in genre analysis. Hermes, Journal of Linguistics no. 16, 39-59.

Blood, R. (2004). How blogging software reshapes the online community. Communications of the ACM, 47(12), 53-55. 
boyd, d. m. (2008). Taken Out of Context. American Teen Sociality in Networked Publics. Doctoral dissertation. University of California, Berkeley.

boyd, d., Golder, S. \& Lotan, G. (2010). Tweet tweet retweet: Conversational aspects of retweeting on Twitter. Proceedings of the $42^{\text {nd }}$ Hawaii International Conference on System Sciences (HICSS). Kauai, HI: IEEE Computer Society.

Bruns, A. (2008). Blogs, Wikipedia, Second Life, and Beyond: From Production to Produsage. New York: Peter Lang.

Bruun, H. (2010). Genre and interpretation in production: a theoretical approach. Media Culture \& Society, vol. 32(5), 723-737.

Dijck, J.v. (2009). Users like you? Theorizing agency in user-generated content. Media, Culture \&s Society, vol. 31(1), 41-58.

Erickson, T. (2000). Making sense of computer-mediated communication (CMC); Conversations as genres, CMC systems as genre ecologies. Proceedings of the $33^{\text {rd }}$ Hawaii International Conference on System Sciences (HICSS). Kauai, HI: IEEE Computer Societ.

Finnemann, N.O. (2005). Internettet i Mediehistorisk Perspektiv. Frederiksberg: Forlaget Samfundslitteratur. Frandsen, K. \& Bruun, H. (2005). Mediegenre, identifikation og reception. MedieKultur, 25(38), 51-61.

Giltrow, J. \& Stein, D. (Eds.) (2009). Genres in the Internet. Issues in the Theory of Genre. Amsterdam and Philadelphia: John Benjamins Publishing Company.

Helles, R. (2009). Personlige Medier i Hverdagslivet. Ph.d.-afhandling, Københavns Universitet.

Herring, S.C., Scheidt, L.A., Wright, E. \& Bonus, S. (2005). Weblogs as a bridging genre. Information Technology \& People, vol. 18(2), pp. 142-171.

Jensen, K.B. (2010). Media Convergence. The Three Degrees of Network, Mass, and Interpersonal Communication. London and New York: Routledge.

Ling, R., Julsrud, T. \& Yttri, B. (2005). Nascent communication genres within SMS and MMS. In Harper, R., Palen, L.A. \& Taylor, A.S. (Eds.). The Inside Text: Social perspectives on SMS in the mobile age, pp. 75-100. London: Klewer.

Lomborg, S. (2009). Navigating the blogosphere: towards a genre-based typology of weblogs. First Monday, 14(5).

Lomborg, S. (2011). Negotiating the Twitter self. On networks of affiliation and relational pressures. Presented at Communication @ the Center, International Communication Association, 26-30 May 2011. Boston, Mass., USA.

Lüders, M. (2008). Conceptualizing personal media. New Media \& Society, 10(5), 683-702.

Lüders, M., Prøitz, L. \& Rasmussen, T. (2010). Emerging personal media genres. New Media \& Society, 12(6), 947-963.

Miller, C.R. (1984). Genre as social action. Quarterly Journal of Speech, 70(2), 151-167.

Miller, C.R. \& Shepherd, D. (2004). Blogging as social action: A genre analysis of the weblog. In Gurak, L., Antonijevic, S., Johnson, L., Ratcliff, C. \& Reyman, J. (Eds.). Into the Blogoshphere. Rhetoric, Community and Culture of Weblogs. http://blog.lib.umn.edu/blogosphere/ (accessed 20.01.11).

Neale, S. (1980). Genre. London: British Film Institute.

Palmer, J. (1990). Genrer og medier - et kort overblik. Mediekultur, 6(14). Aarhus: Sammenslutningen af Medieforskere i Danmark (SMID).

Rettberg, J.W. (2008). Blogging. Cambridge, UK: Polity Press.

Sørensen, A. S. (2008). Den intime blog: autenticitet, affekt og etik. Working paper no. 5 for the research project High-tension Aesthetics. Ethics and Aesthetics in Contemporary Media (2005-2008).

Sørensen, A.S. (2009). Social media and personal blogging: Textures, routes and patterns. MedieKultur, 25(47), 66-78. 
Article: Social media as communicative genres

Swales, J. (1990). Genre Analysis - English in Academic and Research Settings. Cambridge: Cambridge University Press.

Todorov, T. (1990). Genres in Discourse. Cambridge: Cambridge University Press.

Yates, J. \& Orlikowski, W.J. (1992). Genres of organisational communication: A structurational approach to studying communication and media. Academy of Management Review, 17(2), 299-326.

Yates, S.J. \& Sumner, T.R. (1997). Digital genres and the new burden of fixity. Proceedings of the $30^{\text {th }}$ Hawaii International Conference on System Sciences (HICSS). Kauai, HI: IEEE Computer Society.

Stine Lomborg

Assistant Professor, PhD

Film and Media Studies Section,

Department of Media, Cognition and Communication

University of Copenhagen, Denmark

slomborg@hum.ku.dk 